\title{
Tumor types, breast tumor subtypes and extension of systemic disease may influence outcome in cancer patients with brain metastases
}

\author{
Kadri Altundag1 ${ }^{1}$
}

Received: 31 December 2016 / Accepted: 26 February 2017 / Published online: 2 March 2017

(c) Springer Science+Business Media New York 2017

To the Editor,

I want to congratulate Patel et al. [1] for their study. They evaluated oncologic outcomes and toxicities for pre- stereotactic radiosurgery (SRS) (pre-SRS) and post-operative whole brain radiation therapy (WBRT) (post-WBRT) for resectable brain metastases (BM). They concluded that pre-SRS is a viable alternative to post-WBRT for resected BM. Comparing patients characterstics, some tumor types are not equally distributed in both arms (lung cancer 47.2 and $36.4 \%$, melanoma 5.6 and $16.7 \%$ in post-WBRT and pre-SRS, respectively). Outcome of these tumor types with BM may differ. Secondly, though breast cancer BM are distributed equally in both arms, breast cancer HER-2 positive tumor subtype may show better outcome compared to triple negative breast cancer [2]. Therefore, description of breast tumor subtypes may better define the outcome in both arms. Finally, the authors did not give detailed information about the extension of extracranial metastases (bone only vs. visceral metastases) which may indirectly effect outcome of cancer patients with BM.

Compliance with ethical standards

Conflict of interest The author indicated no potential conflicts of interest.

\section{References}

1. Patel KR, Burri SH, Boselli D, Symanowski JT, Asher AL, Sumrall A, Fraser RW, Press RH, Zhong J, Cassidy RJ, Olson JJ, Curran WJ, Shu HG, Crocker IR, Prabhu RS (2016) Comparing pre-operative stereotactic radiosurgery (SRS) to postoperative whole brain radiation therapy (WBRT) for resectable brain metastases: a multi-institutional analysis. J Neurooncol. doi:10.1007/s11060-016-2334-3. [Epub ahead of print]

2. De Ieso PB, Schick U, Rosenfelder N, Mohammed K, Ross GM (2015) Breast cancer brain metastases-a 12 year review of treatment outcomes. Breast 24(4):426-433. doi:10.1016/j. breast.2015.03.007
Kadri Altundag

altundag66@yahoo.com

1 MKA Breast Cancer Clinic, Tepe Prime, Cankaya, 06800 Ankara, Turkey 